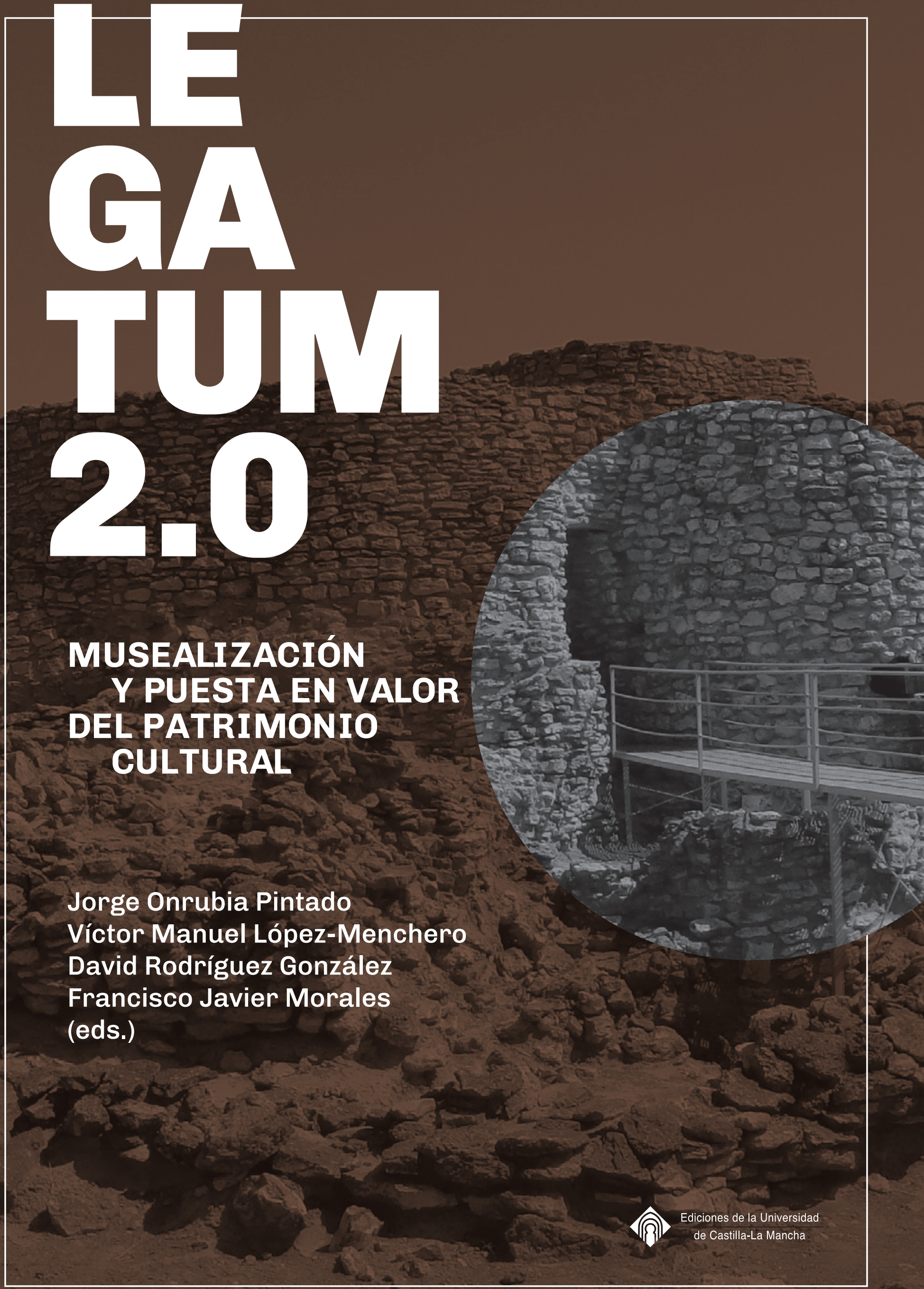





\section{LEGATUM 2.0 \\ Musealización y Puesta en Valor del Patrimonio Cultural}

I Congreso Internacional. 25, 26 y 27 de octubre de 2017

Daimiel. Ciudad Real 



\title{
LEGATUM 2.0 \\ Musealización y Puesta en Valor del Patrimonio Cultural
}

I Congreso Internacional. 25, 26 y 27 de octubre de 2017 Daimiel. Ciudad Real

\author{
Editores: \\ Jorge Onrubia Pintado \\ Víctor Manuel López-Menchero Bendicho \\ David Rodríguez González \\ Francisco Javier Morales Hervás
}

Ediciones de la Universidad

Cuenca, 2020 


\section{LEGATUM 2.0. MUSEALIZACIÓN Y PUESTA EN VALOR DEL PATRIMONIO}

\section{CULTURAL}

Jorge Onrubia Pintado,Víctor Manuel López-Menchero Bendicho, David Rodríguez González y

Francisco Javier Morales Hervás (Eds.)

(C) de los textos e ilustraciones: sus autores

(c) de la edición: Universidad de Castilla-La Mancha

Edita: Ediciones de la Universidad de Castilla-La Mancha.

Colección JORNADAS Y CONGRESOS n. ${ }^{\circ} 22$

Imagen de cubierta: Yacimiento arqueológico de Motilla de Azuer. Santiago López-Pastor. (CC BY-SA 2.0).

El procedimiento de selección de originales se ajusta a los criterios específicos del campo 10 de la CNEAI para los sexenios de investigación, en el que se indica que la admisión de los trabajos publicados en las actas de congresos deben responder a criterios de calidad equiparables a los exigidos para las revistas científicas y capítulos de libros.

Ue Esta editorial es miembro de la UNE, lo que garantiza la difusión y comercialización

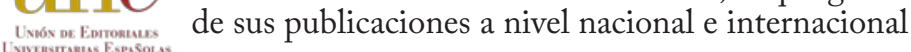

I.S.B.N.: $978-84-9044-402-3$

D.O.I.: http://doi.org/10.18239/congresos_2020.22.00

Composición: Compobell

Hecho en España (U.E.) - Made in Spain (U.E.)

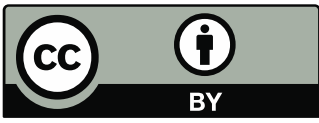

Esta obra se encuentra bajo una licencia internacional Creative Commons CC BY 4.0.

Cualquier forma de reproducción, distribución, comunicación pública o transformación de esta obra no incluida en la licencia Cretative Commons CC BY 4.0 solo puede ser realizada con la autorización expresa de los titulares, salvo excepción prevista por la ley. Puede Vd. acceder al texto completo de la licencia en este enlace: https://creativecommons.org/licenses/by/4.0/deed.es 


\section{ÍNDICE}

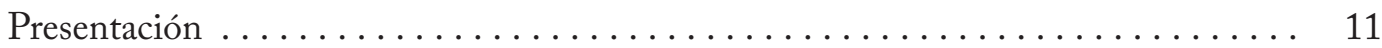

Leopoldo Sierra Gallardo

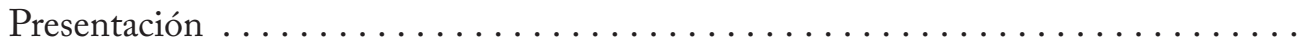

José Julián Garde López-Brea

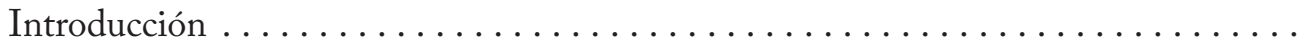

Jorge Onrubia Pintado, Victor Manuel López-Menchero Bendicho, David Rodríguez González y Francisco Javier Morales Hervás

\section{NUEVAS ESTRATEGIAS DE CONSERVACIÓN Y DOCUMENTACIÓN DEL PATRIMONIO CULTURAL}

Conservación y puesta en valor de yacimientos arqueológicos del Bronce de La Mancha: Las Motillas . . . . . . . . . . . . . . . . . . . . . . . . . .

Rebeca Lenguazco González

Conservación in situ del entorno de los Palacios Maestrales: conservación curativa, restauración, arqueología y medios tecnológicos al servicio del museo .......... Raquel Racionero Núnez, y Francisco Miguel Gómez García de la Marina

Recuperación y musealización del patrimonio de Nuestra Señora de las Angustias en Arenas de San Juan, Ciudad Real: contextualización y documentación de un

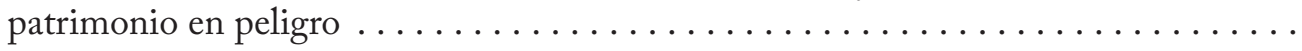
Raquel Racionero Núñez

Conservación y restauración en el oppidum protohistórico del Cerro de las Cabezas

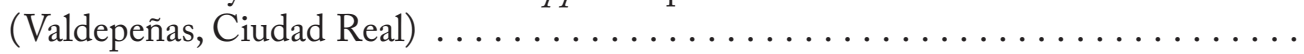
Miguel Carmona Astillero, Tomás Torres González, Domingo Fernández Maroto, Julián Vélez Rivas y José Javier Pérez Avilés

Nuevas tecnologías aplicadas a los estudios patrimoniales. El uso de drones en la

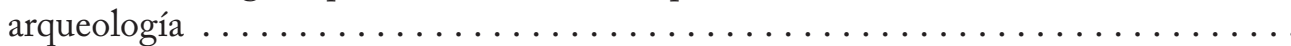




\section{MUSEOS CULTURALES}

Proyecto López Torres...............................

Ricardo Ortega Olmedo

La dimensione narrativa del Museo Archeologico Villa Sulcis di Carbonia in Sardegna Antonio Gambatesa

El Palacio del Segundo Cabo: un museo de nuevo tipo. Estrategias museológicas para la comunicación de procesos culturales $\ldots \ldots \ldots \ldots \ldots \ldots \ldots \ldots \ldots$ Yenny Hernández Valdés

La revolución en los tiempos del cólera. Cuatro museos de La Habana y un futuro

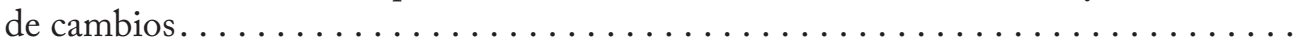
María Florencia Puebla

Diálogo didáctico con las colecciones del Museo del Prado: Una propuesta patrimonial para las Enseñanzas Medias . . . . . . . . . . . . . . . . . . . . . . . . 101 Eva Ma Jesús Morales

Un museo comarcal para un territorio. En busca de su identidad: el Museo de Historia y Costumbres Populares de Los Pedroches . . . . . . . . . . . . . . . . . . . . . 10 $M^{a}$ del Pilar Ruiz Borrega

Do Paleolítico à arte contemporânea: novos discursos museológicos do Museu da Guarda (Portugal) . . . . . . . . . . . . . . . . . . . . . . . . . . . . . . . . . 119 João Mendes Rosa, Vitor Pereira y Tiago Ramos

La valorización del patrimonio artístico religioso de Mallorca a través de los museos de la diócesis en la primera mitad del siglo xx

Sebastián Escalas Sucari

\section{RUTAS TURÍSTICAS, ITINERARIOS CULTURALES Y REDES TERRITORIALES}

La puesta en valor del patrimonio cultural local: las rutas nocturnas "Patrimonio del mercurio" en Almadén (Ciudad Real) . . . . . . . . . . . . . . . . . . . 139 Ana Isabel Trujillo Rodríguez

Traduciendo el pasado. Recursos para la interpretación de restos arqueológicos en la ruta de Caesaraugusta . . . . . . . . . . . . . . . . . . . . . . . . . . . . . . . . . . . . . 149 Rubén Castélls Vela

Puesta en valor del patrimonio cultural en torno al río Tajo: el proyecto "Cuando el río suena" (Talavera de la Reina, Toledo) . . . . . . . . . . . . . . . . . . . . . . . 161 Sergio de la Llave Muñoz y Ana Escobar Requena

Trabajando en red: las Jornadas de Patrimonio Cultural y Natural del Valle de Los Pedroches (Córdoba, España) . . . . . . . . . . . . . . . . . . . . . . . . . 171 $M^{a}$ del Pilar Ruiz Borrega, Manuel J. Parodi Álvarez y Pablo Garrido González ${ }^{3}$

"Qvadraria. Senderos del paisaje y la memoria", un proyecto de puesta en valor del patrimonio cultural

Marta Gómara Miramón

Dialéctica entre turismo cultural y revalorización patrimonial. Un análisis del fenómeno turístico y su impacto patrimonial en la ciudad de Málaga . . . . . . . . . . . . 185 Yolanda Collado Moreno y David Ortega López 
Nuevos formatos de difusión y comunicación patrimonial. Presentación e interpretación del patrimonio cultural . . . . . . . . . . . . . . . . . . . . . . . . . 197

Lourdes Almendros Zaragoza

\section{LA MUSEALIZACIÓN Y DIVULGACIÓN DEL PATRIMONIO ARQUEOLÓGICO}

La estratigrafía arqueológica como elemento de musealización y puesta en valor de los yacimientos arqueológicos: el caso de El Cerro de las Cabezas (Valdepeñas, Ciudad Real) ....................................... 207 Miguel Carmona Astillero y Ana Seisdedos Ribera

En busca de Herna: proyecto de musealización de una ciudad orientalizante en la sierra de Crevillent (Alicante, España) . . . . . . . . . . . . . . . . 217 Alberto J. Lorrio Alvarado, Sara Pernas García, Julio Trelis Marti, Daniel Tejerina Antón y Gustavo Olmedo López

Módulo de interpretación del patrimonio - Red Patrimonio María Naranjo Chacón

La musealización de los yacimientos arqueológicos a finales del siglo XIX. El inicio de una metodología de trabajo.......................... 235 Ana Gómez Díaz

"Pequeños arqueólogos. Talleres didácticos": didáctica, difusión y divulgación del patrimonio...................................... 243

Rubén Pérez López, Silvia del Mazo Fernández y Francisco José Rufián Fernández

Colección Materiales Didácticos Arqueológicos: una publicación pedagógica on-line 253 Óscar Bonilla Santander, Marta Gómara Miramón y Begoña Serrano Arnáez

El complejo ibérico del Cerro de la Merced (Cabra). Un modelo de sinergia institucional para la investigación y difusión del patrimonio arqueológico . . . . . . . . 259 Antonio Moreno Rosa, Mónica Camacho Calderón, Eduardo Kavanagh de Prado y Fernando Quesada Sanz

La Motilla del Azuer y el modelo de gestión del patrimonio cultural del Ayuntamiento de Daimiel 2013-2017

Miguel Torres Mas

El podcast como forma de difusión histórica y patrimonial. El ejemplo de "Plaza de

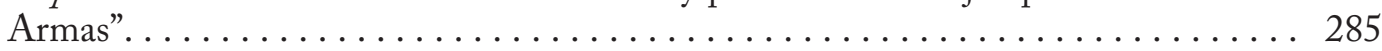
Andrea Menéndez Menéndez, Javier Cuenca Torres, Francisco Guzmán Guzmán, Borja Cruz López y Ramón Vagace Rangel

Concienciación patrimonial e integración social en Los Fayos (Aragón, España). . . 297 Begoña Serrano Arnáez, Óscar Bonilla Santander, Carlos Valladares Lafuente, Alicia Maria Izquierdo, Miriam Pérez Aranda y Ángel Santos Horneros

El patrimonio arqueológico como factor de desarrollo local: el "Cerro del Calvario" en Tabuenca (Aragón, España) . . . . . . . . . . . . . . . . . . . . . . 305 Begoña Serrano Arnáez, Óscar Bonilla Santander, Angel Santos Horneros, Miriam Pérez Aranda, Carlos Valladares Lafuente y Alicia María Izquierdo 


\section{PATRIMONIOS OLVIDADOS, PATRIMONIOS EN PELIGRO}

Puesta en valor y perspectivas de futuro sobre el patrimonio industrial vernáculo de

La Mancha. "Las caleras de Daimiel" . . . . . . . . . . . . . . . . . . . . . . 315

Miguel Torres Mas, Honorio Javier Alvarez García y Manuel Fernández-Infantes

Sánchez-Bermejo

Un ejemplo práctico de puesta en valor del patrimonio documental. El proyecto de innovación docente sobre la exposición «María Encarnación Cabré y el crucero por el mediterráneo (1933)».............................. 325

Jorge del Reguero González

La gran olvidada: La Abadía del III Duque de Alba.

Cristina Muñoz-Delgado de Mata

La construcción del patrimonio cultural inmaterial a través de sus arquitecturas y espacios. El urbanismo de Mutxamel como caso de estudio . . . . . . . . . . . . . 341 María-Teresa Riquelme-Quiñonero

Las fuentes documentales como herramienta para el conocimiento de un patrimonio en peligro: la arquitectura tradicional. . . . . . . . . . . . . . . . 351 Diego Clemente Espinosa

Jardín. Entre la realidad y la idea.

Irene Lavina

Venta de Borondo, patrimonio tradicional manchego en peligro. . . . . . . . . . . . 367

David Cejudo Loro, Silvia Garcia de la Camacha Martin-Pozuelo y Julio Orellana

López de la Franca

Para una arqueología del gusto . . . . . . . . . . . . . . . . . . . 377

Sergio Taranto 


\title{
Jardín. Entre la realidad y la idea
}

\author{
Irene Laviña \\ Universidad Complutense de Madrid \\ http://doi.org/10.18239/congresos_2020.22.37
}

\section{ENTRE LA REALIDAD Y LA IDEA}

Podría decirse que el jardín hace su aparición cuando el ser humano acota una porción de naturaleza e interviene modificándola de una u otra manera: añadiendo o retirando vegetación, rocas, agua, etc. El deseo de controlar la naturaleza, por un lado y, de no perderla a medida que se desarrollan y crecen los espacios urbanos por otro, dará lugar a la creación de diversas soluciones: patios, balcones, parques, etc.

Podemos visitar una importante diversidad de jardines y disponemos de numerosos restos y descripciones de jardines que existieron en el pasado. Pero, además, hay múltiples ideas de jardín. Este trabajo parte de la base de que es tan jardín el que se materializa, como aquel que se mitifica, evoca o sugiere.

Real o ficticio, en tanto que creación humana, el jardín constituye un reflejo del momento en que se construye, transforma y vive. Es, además, un espacio privilegiado para el estudio de la relación entre ciencia, poder, historia y estética. Lo reconocemos como manifestación o expresión artística y como tal, lo valoramos y protegemos confiriéndole un lugar singular dentro de la consideración de patrimonio.

En este trabajo queremos explorar la variedad de miradas que se depositan sobre un tipo de creación artística, cuya definición ha sido tratada en la Carta de Florencia, pero que consideramos que requiere ser ampliada y actualizada ${ }^{\mathrm{I}}$. El objetivo último de estos apuntes es configurar una base para la posterior creación de diseños didácticos centrados en el jardín como instrumento para la enseñanza y la educación.

\section{CONCEPTO: SIGNIFICADO ETIMOLÓGICO}

Rastreando el significado etimológico de diversos vocablos utilizados para denominar al jardín en diferentes lenguas, encontramos ideas que se van repitiendo, pero que también ponen de manifiesto la amplitud de elementos y concepciones que lo enriquecen.

1 Con el fin de adaptarnos a la extensión, se apunta para cada idea una cantidad limitada de ejemplos que creemos que pueden ilustrarla y dejamos de lado, conscientemente, muchos otros igualmente interesantes. 
La antigua palabra persa que denominaba al jardín era pairidaeza, compuesta por pairi, "alrededor", y daeza, "muro", cuyo significado literal sería "recinto cerrado", pero que aludía específicamente al recinto cerrado en el que crecían plantas y árboles. En su diccionario etimológico, Corominas (199I) señala que el término pairidaeza daría lugar a los vocablos griego y latino parádeisos y paradisus respectivamente, que sirvieron para designar a los parques. Posiblemente este préstamo del persa al griego se deba a Jenofonte que en su Anábasis hace referencia a los jardines que tuvo ocasión de conocer cuando participó en una expedición militar a Persia. Por otro lado, la versión griega de la Biblia, tradujo las palabras hebreas que designaban al parque (gan), al Edén (Kden) y al propio Jardín del Edén, con el término parádeisos.

Edén es un vocablo de origen acadio, que se relacionaba con la idea de "puro" en el sentido de natural, acepción que recogía el término hebreo, y a la que se sumarían las ideas de "placer" o "deleite". El diccionario especializado en religión judía editado por Berlín (1997), informa de que, gracias a la traducción de una inscripción bilingüe accadio-arameo encontrada en 1979 en Tel Fekheriyeh, se ha propuesto el significado "bien regado, fructífero". Desde el punto de vista geográfico, "Edén" se referiría a una región mientras que el "Jardín del Edén" o "Paraíso" sería un jardín concreto ubicado en esa región, tal y como parecen indicar algunos fragmentos del Génesis ${ }^{2}$.

Volviendo a lo terrenal, en griego, el término hortos ya aparece en la Iliada 3 haciendo referencia a una porción de tierra delimitada y de uso privativo. La voz latina hortus, sirvió para denominar al jardín, entendido como espacio delimitado normalmente de carácter privado, poblado con vegetación y cuyo fin podía ser estético y alimenticio. En castellano, la palabra huerto se aproximará durante mucho tiempo, más a la idea de jardín de recreo que a la de espacio para la producción de alimento; mientras que su derivado buerta, recogerá en la acepción de tierra de cultivo4.

En japonés se han empleado varias palabras para designar al jardín. Una de las más antiguas es shima, derivada de shime, que significa "artefacto atado" y que designaba la señal que se empleaba para demarcar una propiedad privada. En el caso de una tierra, se hacía un nudo en alguno de los elementos que hubiera en la misma y con el tiempo, la señal pasó a designar lo señalado, es decir, a la tierra en propiedad. Finalmente se entenderá como una porción de tierra escindida o separada del entorno en el sentido de jardín. Actualmente esta palabra se usa para designar a la isla, sugiriendo de nuevo la idea de porción de tierra netamente delimitado. Otra palabra empleada en Japón para denominar al jardín fue senzui, literalmente "montaña y agua", lo que indicaría que el jardín se está identificando directamente con la naturaleza. Actualmente la palabra más empleada para nombrar al jardín es niwa, un antiguo término con el que se denominaba al espacio de arena que antecedía el acceso al salón principal de las viviendas palaciegas. Se trataba de un patio ceremonial cubierto de grava blanca, con solo dos árboles como elementos vivos, y separado del mundo por un muro perimetral. Por tanto, el niwa era un espacio prácticamente vacío, con una fuerte carga simbólica que representaba el lugar de encuentro entre el espacio de los dioses (montaña) y el de los humanos (tierras cultivadas).

Otro vocablo interesante es la palabra hitita gurtas, "fortaleza", cuya raíz encontramos en palabras de diferentes lenguas indoeuropeas. Así, el antiguo término franco gard, que significa "cercado o vallado", pasará al francés como jart, vocablo que traducimos como "huerto-vallado" y que, a su vez, dará origen a la palabra jardín, adoptada por el castellano en el siglo xv. Otros ejemplos serían las palabras garto y garten en alemán, giardino en italiano o garden en inglés. A su vez, la voz alemana gart significa "corro" o "círculo" y la inglesa yard, se refiere, entre otras

2 Génesis, Capítulo 2, Versículos 8-17.

3 Iliada, Canto XXIV, verso 640.

4 El Cantar de Mio Cid (siglo XII) presenta la huerta valenciana como lugar de producción de riqueza. 
cosas, al "patio". Por otro lado, Corominas (I99I) indica que el término parricus, "enrejado", dará lugar al vocablo francés parc que designaba los "terrenos cercados destinados conservar animales salvajes y/o plantas para recreo". En castellano, se adoptará este galicismo como parque o parco, para referirnos a recintos ajardinados para recreo asociados a conjuntos palaciegos. En su diccionario de galicismos, Varela (2009) señala otra acepción, particularmente interesante, que es la de "recinto fortificado o atrincheramiento"; aunque es cierto que este significado apenas se ha desarrollado en castellano y será la idea de recinto ajardinado la que se mantenga. Con el tiempo, este espacio terminará distanciándose físicamente de los conjuntos palaciegos, para designar a los jardines urbanos.

Gracias al Códice Nuttall, sabemos que los aztecas denominaban de forma precisa diferentes tipos de jardines. El vocablo náhuatl Xoxochitla, "lugar de flores", sería el nombre genérico para designar a los jardines, pero Cetzal-Ix y Noguera-Savelli (2014) explican que los jardines también se clasificaron y nombraron de acuerdo con sus destinatarios, de modo que las clases humildes disponían de los Xochichinancali, espacios vallados con flores, mientras que las clases gobernantes disfrutaban de los llamados "palacios de flores" o Xochiteipancalli.

Casi todas las palabras revisadas sugieren la idea de espacio cerrado, a la que debemos añadir la presencia de elementos naturales, normalmente vegetales. Así mismo, intuimos que sensaciones como serenidad, tranquilidad o placer se asocian a varios términos. Pero adicionalmente podemos rastrear multitud de ideas y usos que nos adentran en este concepto dando forma a una realidad más compleja.

\section{LUGAR DE ORIGEN, TRÁNSITOY FIN}

Podemos decir que el jardín nos acompaña a lo largo de nuestra vida, acogiéndonos desde nuestra niñez en el jardín de infancia y procurándonos un lugar para descansar al final. También sabemos que, para algunos, el jardín constituye una meta, un objetivo en sí mismo, que se espera alcanzar como recompensa.

Si nos centramos en el ámbito de la ficción, encontramos numerosos mitos en los que el jardín se presenta como el origen de la vida. El Antiguo Testamento ${ }^{6}$ relata como dios creó al hombre y le permitió asentarse en un jardín. Leyendo el pasaje intuimos que el sentido de la existencia de Adán sería habitar y cuidar ese jardín. Pero este relato no es el único ni el primero que plantea esta idea primigenia. Krammer (1985) pone de relieve la relación existente entre los relatos míticos sumerios y hebreos y afirma que no existe "ninguna duda de que los sumerios influyeron profundamente sobre los cananeos, antecesores de los hebreos en Palestina" (p.I2I). El poema mítico sumerio Enki y Ninhursag (siglo xviII a.C.), narra que los dioses vivían en el jardín que habían creado para sí mismos y que, para evitar ocuparse de sus cuidados, el dios Enki creó a los seres humanos utilizando la sangre de uno de los dioses que murió sacrificado para ello. Por su parte, el poema babilónico de la creación, el Enuma Elish (siglo XII a.C.), describe la creación de un jardín a partir del cuerpo despedazado de la diosa Tiamat.

Vemos que el jardín, además de ser origen de la vida y espacio para habitar, es también un lugar ligado a la muerte. Sabemos que quebrantar las normas de determinados jardines podría conllevar severos castigos, incluida la muerte o que, además de plantas medicinales, en los jardines se cultivan venenos. Mención especial merecen los Jardines de Adonis, pequeños y efímeros jardines elaborados en recipientes a modo de rito funerario para representar la muerte prematura en Grecia. No podemos dejar de comentar el reciente descubrimiento de un jardín funerario de unos 4.000 años de antigüedad en Luxor, sobre el que José Manuel Galán, director

5 Manuscrito prehispánico mixteca.

6 Génesis 1:11. 
del proyecto Djehuty, afirmaba en prensa7 que "ésta es la primera vez que se ha encontrado físicamente uno de ellos, es la primera vez que la arqueología confirma lo que se deducía por la iconografía".

No son pocas las religiones que prometen paraísos al final de nuestras vidas. Desconocemos si existen o no esos prometidos paraísos y nuestras posibilidades de alcanzarlos son inciertas, pero lo que sí podemos documentar es la existencia y permanencia de jardines construidos para el descanso definitivo de nuestros restos: son los cementerios. Quizás lugares de tránsito, un preludio de lo que está por venir.

\section{REFUGIO. NATURALEZA A MEDIDA DEL SER HUMANO}

Un jardín es un refugio que protege de la hostilidad de la naturaleza. El jardín-paraíso terrenal, la naturaleza a medida del ser humano, frente al hostil entorno en el que nacen las primeras civilizaciones o a la experiencia infernal que descubren los conquistadores europeos en las selvas americanas, africanas, asiáticas y oceánicas. Recordemos que varios términos empleados para designar al jardín hacen referencia a la idea de espacio cerrado. Esto sugiere que la función de estos jardines era protegerse o distanciarse de un entorno hostil, por el rigor del clima, por la escasez de vegetación o por la dureza excesiva de otro tipo de condicionantes. Podemos imaginar que, tanto en el caso de los jardines egipcios como en el de los pairidaeza persas, la aridez del entorno y la escasez de la vegetación contrastarían enormemente con los vergeles creados por el ser humano, un logro que debió constituir el principal alimento del mito del paraíso terrenal. Las descripciones que los viajeros occidentales de la antigüedad hicieron de los jardines persas, contribuirían a la mitificación del jardín oriental, confundiendo aquello que había sido concebido y realizado por el ser humano con una creación divina. Marcos Martínez (2007) proporciona un amplio repertorio de escritos realizados por viajeros que deslumbrados describen estos jardines persas. Estas descripciones permiten comprender que, gracias al trabajo del ser humano, su ingenio y su capacidad de construcción, es posible disfrutar de espacios inesperados, casi ajenos al propio emplazamiento, en los que la protagonista es una naturaleza modelada. Espacios que sin las correspondientes explicaciones técnicas parecerían mágicos, pero que, incluso con ellas, crean en el imaginario occidental una idea de paraíso trascendente y mística.

La maqueta de un jardín doméstico encontrada en la tumba de Meket-re (2000 a.C.) confirma la idea de que se trataba de un espacio aislado, un refugio, que mantenía a raya al mundo exterior. También en Mesopotamia el jardín tendría esta función protectora, tal y como confirman las numerosas descripciones del Dilmun, un lugar mítico y paradisíaco, del que el poema sumerio Enki y Ninhursag, afirma que es "un país puro, limpio y brillante, donde el león no mata ni el lobo se apodera del cordero" (Kramer, I985: I22), un lugar en el que el dolor y la muerte están ausentes. Los musulmanes adoptarán y difundirán el modelo del jardín persa, a partir del que se generará una cosmogonía que finalmente pasará a la representación del paraíso musulmán. En el Corán se describe este jardín como un inmenso espacio cerrado, sombreado, generosamente regado por el agua de ríos y arroyos y repleto de árboles frutales cargados de alimentos deliciosos. Una naturaleza exuberante, pero a medida del hombre, donde el azufaifo no tiene espinas ${ }^{8}$, concebido para el deleite de todos los sentidos y para dar descanso y refugio del alma. También la mitología china recoge la existencia de un jardín localizado en el monte Penglai, en el que no existe el dolor, dónde nunca es invierno, que cuenta con provisiones de arroz y vino ilimitadas y cuyas frutas curan todo tipo de enfermedades (Seguí, 20I4).

7 Noticia recogida en National Geographic España, el 4 de mayo de 2017. <http://www.nationalgeographic. com.es/historia/actualidad/los-arqueologos-espanoles-del-proyecto-djehuty-descubren-jardin-funerarioegipcio_11457/1>

8 Sura 56, 28. 
En México, la cultura nahuatl creó su propio paraíso, el Tlalocan, un lugar tranquilo, repleto de toda clase de árboles frutales y plantas comestibles que Bernardino de Sahagún tradujo como "tierra de riquezas o paraíso terrenal". Pero lo que encontraron en aquellas tierras los conquistadores europeos fue desconcertante. Los escritos del primer viaje de Colón dan cuenta de una naturaleza intrincada y excesiva, pero descrita a partir de elementos conocidos que le permitirían hacer comprensible lo que veía a través de clichés literarios: "lo que describe Colón en su texto es un locus amoenus y poco importa el paisaje verdadero"(Wahlström, 2009: I6). Por el contrario, los escritos de López de Gómara', dejan claro que aquellas tierras diferían mucho de lo conocido hasta el momento, especialmente en lo referido al espacio natural, su geografía, su flora y su fauna. No sorprende que, inicialmente, los europeos llegaran a identificar esa exuberancia de las selvas americanas con el paraíso terrenal. Sin embargo, a medida que se adentran en los nuevos territorios, su experiencia no pudo resultar más dura. Los relatos de Hernán Cortés ${ }^{\mathrm{To}}$ y Bernal Díaz del CastilloII sobre su expedición a Tenochtitlan (I5I9-I52I) no dejan lugar a dudas: aunque describen admirados los lugares en los que la naturaleza parece controlada, en general esta se convierte en una amenaza constante. Como señala Monteleone (1998), "la naturaleza, entonces, dista de ser dominada, se está, como por un momento, fuera de la cultura” (p.243). Así, el jardín permite aventurarnos en la naturaleza, desde la seguridad, convirtiendo nuestra experiencia en un paseo lúdico, que nada tiene que ver con la percepción del entorno como un elemento hostil que pone a prueba nuestra capacidad de supervivencia. Un medio en el que la mayoría de nosotros seríamos incapaces de sobrevivir, pero que nuestros sentidos siguen buscando.

Pero el jardín no solo nos protege de esa naturaleza que nos supera fragmentándola, delimitándola y domesticándola para despojarla de su magnitud y disponer de ella a nuestra medida; además nos protege de la ciudad, que de forma artificial nos distancia de nuestro elemento natural.

\section{PROVEEDOR DE ALIMENTO: HUERTO}

En la concepción del jardín como paraíso se repite constantemente la idea de que es fuente inagotable de alimento. Esto refleja una realidad que caracteriza al jardín desde su aparición: el hecho de que es un terreno para cultivar y del que obtener alimentos.

En su descripción del Estado sumerio de Lagash, Kramer (1985) afirma que la posesión de un jardín o de una cabeza de ganado se consideraba imprescindible para garantizar la supervivencia, lo que explica que Urukagina (2380-236o a.C.) decretase leyes tendentes a proteger a la población más débil: "ya no había ningún dignatario que se atreviese a usurpar el jardín de la madre de un hombre pobre, despojando los árboles y llevándose los frutos, como era costumbre antes" (Kramer, 1985:53). Otro ejemplo paradigmático del jardín concebido como huerto es el romano, "campo del pobre" y "despensa de los plebeyos" ${ }^{2}$, cuyo origen probablemente estuviese en el hortus situado junto a la cocina, en el que se cultivaban plantas y verduras para consumo propio. Con el tiempo, hortus fue la palabra empleada para denominar al jardín ornamental urbano: jardín o huerto o ambas cosas a la vez, lo cierto es que un huerto podía integrarse sin problema en un jardín ornamental, fundiendo así las funciones estética y productiva.Importantes fueron también los huertos medievales. Entre ellos mencionaremos los asociados a monasterios y conventos, unos jardines concebidos para acompañar la vida espiritual de los habitantes de estos lugares, pero, sobre todo, para proveer de alimentos y medicamentos. Mientras, en el otro extremo del mundo, los aztecas desarrollaron un ingenioso sistema para ampliar el terreno habitable en un territorio cuya superficie estaba cubierta de pantanos. También fue necesario

9 López de Gómara (1552) Historia de la conquista de México.

10 Cortés (1519-1526) Cartas de relación.

11 Bernal Díaz del Castillo (1632) Historia verdadera de la conquista de la Nueva España.

12 Plinio (siglo I) Historia Natural, (libro XIX, 52). 
adoptar este tipo de solución para la creación de espacios para el cultivo. Así, aparecen las chinampas, verdaderos jardines flotantes, que sirvieron para cultivar flores y plantas alimenticias.

En el caso de las ciudades occidentales modernas, la proliferación de huertos urbanos ha estado ligada con frecuencia a periodos de crisis de diferente naturaleza (pobreza urbana, supervivencia en períodos bélicos) o a otro tipo de fenómenos sociales como el ecologismo o la participación ciudadana. Destacamos los llamados war gardens surgidos durante las guerras mundiales, a veces de forma espontánea, pero otras por iniciativa institucional mediante programas respaldados por intensas campañas transmitidas a través de carteles, documentales, programas de radio, boletines educativos, etc. Un ejemplo interesante son los US School Garden Army, un programa desarrollado durante la Primera Guerra Mundial, que movilizó a los escolares difundiendo la idea de que "cada niño y cada niña debe ser un productor. Productividad es el primer principio en la educación. El cultivo de plantas y animales debe formar parte del programa escolar. Este es el objetivo del Ejército de los Jardines Escolares de los Estados Unidos" (Hayden-Smith, 2006: 2) ${ }^{\mathrm{r}}$. Otro fenómeno interesante es la aparición de huertos comunitarios, animado por la recesión económica de las décadas de los años 60 y 70 . En este escenario de crisis económica, diversas ciudades sufrieron graves procesos de degradación y abandono de los centros y, en algunos casos, la población se organizó y buscó estrategias para frenarlos. Diversos grupos ocuparon espacios baldíos para la construcción de huertos y jardines. El origen de este tipo de iniciativas lo situamos en Estados Unidos, donde destacamos el proyecto People's Park en Berkely y la llamada Green Guerrilla, nacida a partir de la iniciativa de la artista Liz Christy en Nueva York. Este fue el inicio de un movimiento que tendría consecuencias relevantes, por las implicaciones para los hábitos de consumo, las relaciones sociales y los derechos de la tierra o la implementación de modelos innovadores de autogestión.

\section{LABORATORIO. ESPACIO PARA EL ESTUDIO Y LA EXPERIMENTACIÓN}

El jardín también es proveedor de materia para el conocimiento y la experimentación. Adquiere, por lo tanto, una dimensión científica, técnica y empírica.

De forma inconsciente o planificada, el traslado de elementos naturales es un fenómeno que siempre nos ha acompañado. Son varios los ejemplos tempranos de organización de expediciones para la búsqueda de especies vegetales y animales y parece que los jardines han sido el marco perfecto para un tipo de coleccionismo que reúne y estudia, aclimata y experimenta con especies vegetales y animales.

Vovides, Linares y Bye (2010) consideran que las culturas prehispánicas mexicanas venían desarrollando desde el siglo xiI, un tipo de jardín que responde a lo que denominamos jardín botánico. Según Vergara (2009), en estos jardines se desarrolló un verdadero conocimiento científico, asentado sobre la observación, clasificación y experimentación de las cualidades de las plantas y estrechamente asociado al estudio de la medicina. Aunque no podemos desvincular la creación de este tipo de jardín del sistema de creencias religioso, el impulso científico parece incuestionable. León-Portilla (1959) considera que en época prehispánica "se tenía conciencia de que además del saber estrictamente religioso, había otra clase de saber, fruto de observaciones, cálculos y reflexiones puramente racionales, que aun cuando podían relacionarse con ritos y prácticas religiosas, eran en sí de un género distinto" (León-Portilla, 1959: 38). El historiador Del Paso y Troncoso afirmaba que "el principal objetivo por el cual se establecieron los jardines botánicos de esta época fue el de crear centros experimentales de plantas regionales o de otras localidades para conocer o confirmar sus propiedades" (Vovides et al., 2010: 68). Importantes fueron los jardines creados por Moctezuma (I466-I520), que se ocupó extensamente del cultivo

13 Texto extraído de un manual escolar de 1920 supervisado por la Oficina de Educación de California. 
de plantas medicinales cuyas propiedades se experimentaban de forma sistemática. Además, diversos testimonios, como el de Hernán Cortés, señalan la existencia de un jardín zoológico con colecciones de animales, entre las que figuraría una de humanos, compuesta por personas con malformaciones por alteraciones genéticas o enfermedades.

Esta relación entre la creación de jardines botánicos y el desarrollo de la investigación médica la podemos encontrar también en China, en la India o en la Europa medieval. Vergara (2009) señala que, coincidiendo con un profundo cambio en la cultura científica europea, la exportación de especies vegetales americanas a Europa y de los conocimientos prehispánicos sobre el cuidado de jardines y cultivos, supusieron un impulso decisivo para la aparición de los primeros jardines botánicos en Italia a mediados del siglo xvi.

El jardín ha sido además un espacio privilegiado para la experimentación de formas espaciales y del empleo de nuevas técnicas y materiales. Arquitectura y urbanismo mantienen una estrecha relación con el desarrollo del jardín, donde con frecuencia se han experimentado soluciones y diseños. Han permitido la introducción de innovaciones decisivas en el ámbito del diseño urbanístico. Adicionalmente, el jardín ha dado la oportunidad de ensayar avances técnicos y tecnológicos diversos. Entre otros, algunos de los más relevantes relacionados con la conducción y drenaje de agua, o soluciones para favorecer el cultivo y crecimiento de diversas plantas en entornos hostiles (tratamiento de la tierra, creación de pantallas vegetales, construcción de invernaderos, etc.).

\section{UN JARDÍN ES UNA IMAGEN}

Tanto el jardín en su conjunto como cada uno de los elementos que lo configuran pueden adquirir valores simbólicos cuya lectura debe realizarse en clave religiosa, política, económica o social. Como otras creaciones humanas, el jardín funciona como un transmisor de mensajes que permite exaltar unos valores y reforzar la imagen de poder.

A lo largo de la historia, muchos jardines han sido creados partiendo de creencias y concepciones míticas y religiosas. En el caso del taoísmo chino, el agua, la piedra y todos los elementos que pueblan el jardín adquieren valores simbólicos. Además, el jardín se convertirá en el espacio perfecto para el aislamiento y la contemplación de unos elementos naturales revestidos de un carácter místico. Un jardín taoísta singular es el miniaturizado, cuya realización y observación sería también expresión de veneración a una naturaleza que aparece esencialmente recogida en pequeños recipientes. Según explica Stein (20I6), la reducción del tamaño del agua, las rocas y la vegetación potenciaría el poder que estos elementos tienen en la naturaleza a escala real, de modo que "la reproducción de un objeto natural adquiere más valor según se aleja de sus dimensiones reales pues este objeto se carga de un poder religioso difuso conforme va empequeñeciendo su medida" (Stein, 2016: 16). Esta idea sugiere una práctica que aparece recogida en algunos relatos: "el iniciado se convierte en pequeño y desaparece en el interior del jardín en miniatura en una especie de retiro que no es más que un intento de reintegrarse a la naturaleza primitiva, el estado primordial del origen”(Stein, 20I6: I6). Además, los árboles miniaturizados, retorcidos y nudosos, evocan la ejercitación necesaria para seguir el camino del tao: los árboles adquieren ese estado del mismo modo que el ser humano se moldea a sí mismo.

Tanto el jardín en sí mismo como los elementos que contiene confieren el prestigio que se desea adquirir. Este esquema se repetirá a lo largo y ancho del mundo y en diversos momentos. Un ejemplo significativo es el de los parques de caza, cuya existencia se remonta a Mesopotamia, donde se crearon extensos recintos cerrados con animales autóctonos y especies exóticas. Eran espacios arbolados, con avenidas para carros y dotados de las correspondientes redes de riego, cuya finalidad era la práctica de la caza como símbolo de las cualidades militares y polí- 
ticas del gobernante. En Egipto y en China, la incorporación de animales y especies vegetales de procedencia lejana era una manera de evocar las conquistas y territorios anexionados por el gobernante. Sería una manera de justificar la política expansionista de Tutmosis III (siglo XV a.C.) (Velasco, 20I6) o la política de unificación y centralización llevada a cabo por la dinastía Qin a partir del siglo III a.C. Procesos que irían acompañados de la correspondiente simbología y que se materializarían, entre otras cosas, en la construcción de jardines que debían acoger los especímenes vivos de las regiones anexionadas. Así, la construcción de estos microcosmos debemos interpretarla como una demostración de poder político. Otro ejemplo paradigmático lo encontramos en el proyecto de construcción de los jardines de Versalles, construidos al servicio de los planteamientos del absolutismo real y de la proyección de la imagen del rey: todo en este jardín formaría parte de un ejercicio de propaganda tendente a la identificación de Luis XIV con la idea de Príncipe de la Razón, divinidad o inmortalidad, etc. (Soto, I982).

Otra de las lecturas más inmediatas que podemos hacer de un jardín es la de su conversión en elemento visible del estatus económico y social de su propietario. Los jardines se convierten en espacios para la ostentación, de las clases privilegiadas próximas al poder, pero también de la burguesía, que se ocupará de hacer visible y tangible su ascenso social. La idea sería aislarse en un modo de vida reservada a unos pocos al tiempo que se crean mecanismos para hacerla visible. En este caso, la riqueza material funcionaría en realidad como un reflejo de la virtud inherente de su poseedor. Ejemplo de este proceder serían los jardines romanos, que se convirtieron en espacios para la escenificación de los rituales sociales.

\section{ESPACIO DE OCIO. ESPACIO PARA DISFRUTAR: RECOGIMIENTO Y SOCIALIZACIÓN}

De las diversas concepciones del jardín que hemos ido viendo se desprenden particulares formas de experimentar o vivirlo. Unas veces nos adentramos en el jardín buscando intimidad y otras encontramos oportunidades para la socialización. En él se descansa o se medita, pero también se convierte en lugar de juego y recreo, en espacio para el ocio y la diversión, abriendo un amplio abanico de posibilidades dependiendo de las condiciones y dotaciones de las que esté provisto.

En aquellos casos en los que el jardín es un espacio de acceso restringido, uno de sus potenciales usos es el del aislamiento y el recogimiento. El disfrute en soledad de la soledad y de uno mismo o la búsqueda de una conexión particular con la naturaleza, el conocimiento o las creencias íntimas. Así sucede en el caso del jardín chino que es, ante todo, un espacio donde encontrar una unión con la naturaleza caracterizada por la armonía y la intimidad (Cervera, 2000). En este sentido, quizás el ejemplo más extremo de aislamiento lo encontramos en los jardines en miniatura, que exigen un complejo ejercicio de sugestión para introducirse y perderse en su interior. No obstante, sabemos que en los jardines chinos también se producían reuniones de eruditos para escribir y recitar poemas, escuchar o interpretar música, contemplar antigüedades y otros objetos de valor, etc. O que se convertían en imponentes escenarios para la celebración de espectáculos ${ }^{1 /}$.

En occidente encontramos curiosidades como Bomarzo, un jardín para sorprender y jugar, con atracciones singulares y juegos simbólicos a modo de acertijos. Y por su parte Versalles, no será solo una obra de propaganda política. Además, se convirtió en el escenario ideal para una vida cortesana dedicada al capricho y la diversión.

La apertura de espacios para el esparcimiento público será una práctica que, de forma aislada, encontramos a lo largo de la historia. Localizamos alusiones muy tempranas a espacios ajardina-

14 En el Sakuteiki, tratado de jardinería chino del siglo xI, se dan indicaciones precisas sobre las medidas que debían tener los bordes de los lagos para acoger este tipo de evento o el tamaño de la isla destinada al grupo de músicos. 
dos de uso público que tomamos con prudencia: Kramer comenta la preocupación que suscitaba en la antigua Summer, la presencia de "muchachos que vagabundeaban por las calles y hacían el golfo en los jardines públicos" (Kramer, 1985: 31). Pero al margen de ejemplos aislados, hasta el siglo xviII, no comenzará un proceso de "democratización del paraíso" que, con la Revolución Francesa, adquirió un cariz reivindicativo, que incluía el derecho al ocio y el disfrute de "placeres" que hasta entonces habían estado reservados a unos pocos. Estas nuevas exigencias requerían de "zonas de esparcimiento convenientemente equipadas". (Rodríguez y Prieto, 1997: 397).

El siguiente paso sería la creación de nuevas dotaciones públicas, fenómeno que cobrará especial relevancia a partir del siglo xIx, momento en el que jardines y parques se convierten en equipamientos imprescindibles con implicaciones en el trazado urbano, la vida social, etc. La Revolución Industrial y el rápido crecimiento de las ciudades cambiaron radicalmente su aspecto y generaron nuevas necesidades, entre las que destacó la creación de espacios abiertos. Un caso temprano fue el de Londres, donde la creación de los barrios nuevos se proyectó con el diseño de plazas según el modelo del Covent garden. También en Gran Bretaña, en Liverpool, encontramos uno de los primeros parques municipales de acceso público y no restringido: en I844 se inauguró Birkenhead Park, un jardín con cierto aire señorial, cuyo diseño paisajístico, según Olmstead "había alcanzado aquí una perfección como nunca habría soñado" "s. Años después, él y Calvert Vaux serán los encargados del proyecto de transformación en jardín del enorme espacio baldío que había en el centro de Manhattan.

\section{UN JARDÍN ES SALUD FÍSICAY MENTAL}

Los jardines son elementos indispensables para el bienestar del ser humano. Ya hemos hablado del papel del jardín como farmacopea, pero no podemos obviar su relevante papel de mediador entre el ser humano y la ciudad. A medida que la vida urbana se desarrolla y que las ciudades crecen, a medida que la cotidianeidad se va distanciando del campo, el cielo y la vegetación, el jardín se convertirá en elemento indispensable para la salud física y mental de los habitantes de las ciudades.

Uno de los factores más determinantes para la creación de jardines y parques públicos fue la búsqueda de soluciones a los problemas de insalubridad de las ciudades industriales. Los movimientos higienistas del siglo XIX introdujeron su ideario influyendo de forma decisiva en la mejora de las ciudades. Jugo (2007), afirma que el urbanismo moderno "no nace de los estudios de los arquitectos, sino precisamente de la experiencia de los defectos de la ciudad industrial y gracias a los técnicos e higienistas que se esfuerzan por dar con el remedio" (p.5). Adicionalmente se proponían mejorar la calidad de vida de los ciudadanos mediante la creación de espacios verdes en los que fuese posible descansar del ajetreo urbano: "la construcción de estos espacios se corresponde tanto con las necesidades sociales como con las emocionales de los habitantes de la ciudad" (Ruiz, 20I2: 155). Jardines y espacios arbolados, contribuirían al embellecimiento de las ciudades y serían, además, un medio para satisfacer esa necesidad de sosiego y bienestar al tiempo que proporcionarían aire limpio y salud (Rodríguez y Prieto, 1997). Se trataba de atender a las necesidades físicas y emocionales de una sociedad inevitablemente afectada por las condiciones de vida que ofrecían las ciudades de la época.

Actualmente la OMS considera indispensable la presencia de espacios verdes en las ciudades y numerosos estudios señalan los innumerables beneficios que estos aportan.

Un ejemplo actual que pone de relieve la interrelación entre el entorno y nuestro bienestar son los Jardines fisiológicos realizados en el año 2000 por los arquitectos Décosterd \& Ram en

15 Olmstead (1851) Walks and Talks of an American Farmer in England. 
La Neuveville, Suiza. Su diseño se estableció en base a la creación de itinerarios, con presencia de plantas que fuesen activando nuestro sistema fisiológico mediante la intervención de procesos químicos, biológicos y electromagnéticos. Así, la naturaleza se contemplaba como dimensión biológica no material o visual, que se incorpora a nuestra experiencia (Lamúa, 20I5).

\section{REFERENCIAS BIBLIOGRÁFICAS}

BerLín, A. (Ed.) (1997): Oxford Dictionary of the Jerwish Religion, Oxford University Press, Oxford.

Cervera, I. (2000): «Paisajismo y Jardín en China», en Ars Longa, no 9, pp. 27-35 [9/6/r8] <DOI: https:// doi.org/10.7203/arslonga.9-10.II760>

Cetzal-Ix, W., y Noguera-Savelli, E. (20I4): «Jardines prehispánicos de México», en Herbario CICY, no 6, pp. 109-Іт2 [то/6/18]

<www.cicy.mx/Documentos/CICY/...Herbario/20I4/20I4-II-I3-Cetzal-Noguera.pdf>

Corominas,J., y Pascual,J.A. (199i): Diccionario crítico etimológico castellano e hispánico, Gredos, Madrid.

Hayden-Smith, R. (2006): Soldiers of the Soil: A Historical Review of the United States School Garden Army, University of California, California.

Jugo, L. (2007): Sobre el urbanismo y sus planteamientos desde el siglo XIX hasta hoy [10/6/18] <www.saber. ula.ve/bitstream/handle/r23456789/.../urbanismo-planteamiento.pdf? >

Krammer, S.N. (1985): La historia empieza en Summer, Ayma, Barcelona.

LAMÚA, C. (2015): Intervenciones artísticas en el territorio: lugares anómalos generados por la pulsión de lo emocional, UCM, Madrid.

Martínez, M. (2008): «Descripciones de jardines y paisajes en la literatura griega antigua», en Estudios griegos e indoeuropeos, $\mathrm{n}^{\circ} \mathrm{I} 8, \mathrm{pp} .279-318$.

Monteleone, J. (1998): El relato de viaje. De Sarmiento a Umberto Eco, El Ateneo, Buenos Aires.

Rodríguez,E.J.,y Prieto,J.M.(I997): «Haciendo el Jardín de las Delicias. Ficción y realidad en relación a los ámbitos de recreo público decimonónicos», en Archivo español de arte, LXX, nº 280, pp.397-418.

Ruiz, E.M. (20I2): «El jardín como elemento integrador del hombre en la metrópoli», en Arte, Individuo $y$ Sociedad no 24 (I), pp. I47-I57 [6/6/18] <http://dx.doi.org/ro.5209/rev_ARIS.20I2.v24.nI.38049>

Seguí, V. (20I4): Jardines de Extremo Oriente. China [9/6/18] <http://alenarterevista.net/jardines-deextremo-oriente-china-por-virginia-segui/>

Soто, V. (1982): «El jardín madrileño en el siglo xix: propuesta y realidad», en Anales del instituto de Estudios Madrileños, $\mathrm{n}^{\circ}$ I9, pp. 95-I24.

SAhagún, B. (I990): Historia general de las cosas de la Nueva España, I5II, Consejo Nacional para la Cultura y las Artes, México D.F.

Stein, R. (2016): Jardines en miniatura de extremo oriente. Ritos y leyendas. Miraguano Ediciones, Madrid.

Varela, E. (2009): Diccionario de galicismos de los siglos XVI y XVII, CSIC, Madrid.

VeLAsco, A. (20I6): El jardín botánico de Tutmosis III en Karnac [5/4/r8] <https://papirosperdidos. com/2016/o9/25/el-jardin-botanico-de-tutmosis-iii-en-karnak/>

VERgARA, M.C. (2009): La creación de jardines botánicos y el manejo del paisaje en las universidades, Universidad de Guanajuato, Guajanuto.

Vovides, A.P., Linares, E., y Bye, R. (20I0): Jardines botánicos de México: historia y perspectivas, Secretaría de Educación de Veracruz, Veracruz.

Wahlström, V. (2009): Lo fantástico y lo literario en las Crónicas de Indias [9/4/18] <http://studylib.es/ doc/66o9303/lo-fant $\% \mathrm{C}_{3} \%$ Asstico-y-lo-literario-en-las-cr\% $\mathrm{C}_{3} \% \mathrm{~B}_{3}$ nicas-de-indias-es > 